\title{
Knowledge Sharing Practices of Commercial Bank of Ethiopia Hossaena Town Branches
}

\author{
Fantaye Ayele \\ School of Informatics, Wolaita Sodo University, PO box 138, Wolaita Sodo, Ethiopia
}

\begin{abstract}
Know days the banking sector is operating in a highly dynamic and competitive environment. Thus, with these driving forces banks are starting to understand the relevance and importance of financial knowledge sharing. The major purpose of this study was to assess the knowledge sharing practices of employees on the Commercial Bank of Ethiopia, Hossaena town branches. To this end, data were collected from a randomly selected 85 employees working in thirteen branches found in Hossaena town. Both descriptive and inferential statistical analyses were employed for analyzing the quantitative data obtained. The major factors found to influence the knowledge sharing practices of commercial Bank Ethiopia were scarcity of Information Technology infrastructures, lack of time, and lack of formal and informal awareness creating activities, lack of interaction among the staff members and physical work environment and office layouts. Also, among the four modes of the Socialization, Externalization, Combination and Internalization models of knowledge sharing, the combination was found to be a widely practiced mode of knowledge sharing. Thus, to have a better environment of knowledge sharing practices, focusing on the socialization, internalization, externalization and combination modes together seems inevitable.
\end{abstract}

Keywords: Knowledge sharing, combination, internalization, socialization

DOI: $10.7176 / \mathrm{IKM} / 9-11-03$

Publication date: December $31^{\text {st }} 2019$

\section{Introduction}

The Commercial Bank of Ethiopia was established in its present form by a merger of one the nationalized private banks with that of the publicly-owned commercial bank by proclamation No.184(1980). Since 1992 Ethiopia has been gradually liberalizing its financial sector. The modern world is characterized by dynamic and continuous technological advancement; and to cope with this change and to survive, organizations must become more flexible and open their doors for change. Since the 1950s, a central question in international development has been how knowledge can best be generated, mobilized, made available, applied and adapted to improve the human condition (IFAD, 2007). In today's world, knowledge is still considered as power, and it is; ,but the understanding has changed considerably, particularly from the perspective of an organization, knowledge must be shared (Mothe et al., 2000). Depending upon the nature of knowledge, knowledge divided into two forms: Tacit and explicit. Tacit knowledge is the knowledge stored in one's brain whereas explicit knowledge is the knowledge contained in documents or other forms of storage other than the human brain (Najibullah et al., 2012). Both types of knowledge can be produced as a result of interactions in the environment or innovations by the individuals themselves. It has been shown that the organizations that share knowledge among its management and employees could grow stronger and becomes more competitive (Jakarta and Ratulangi, 2008). Yang (2011) further stated that the development and efficient application of Information and Communication Technologies (ICTs) in the business field, particularly in the banking sector, could enable the shaping of the world economy. The heart of these changes places into managing the knowledge of the organizations. Hence, the essentiality of knowledge sharing in the continuously changing world of business is found to be unquestionable. Consequently, the question of survival and development makes the use of the right information and knowledge management system critical for financial institutions, like the banking sectors.

\section{Statement of the Problem}

According to Aidemark (2009), from the total knowledge of an organization, $80 \%$ is evidenced to be in the mind of individuals and the remaining $20 \%$ is available in the form of explicit knowledge. Unless individuals interact and create mechanisms for converting and sharing this knowledge among themselves, their effort will only fetch limited success in their organizations. Unquestionably, it needs good and sound ways to capture and share knowledge of the employees. Having this fact in mind, conducting research on knowledge sharing and identifying barriers that could influence or hinder it becomes more justifiable. Besides, knowledge sharing practice can be influenced by several different factors. Among the many factors, individual behaviors of employees, organizational cultures, the existence of adequate Information Technology infrastructures and employee communication are the major ones that have the power to influence knowledge sharing practices in the banking sectors (Seyyed et al., 2012). Hence, a detail investigation of those factors that determine the degree of practicing knowledge sharing in that specific organization seems vital. This study aims to investigate the 
prominent factors and their influence on the knowledge sharing practice of employers.

\section{Objectives}

\subsection{General objectives}

The general objective of this study was to assess knowledge sharing practices of employees on the benefits of commercial Bank of Ethiopia Hossaena town branches

\subsection{Specific Objectives}

The specific objectives of the study are to:

$>$ Identify the major factors influencing knowledge sharing practice among employees of commercial Bank of Ethiopia Hossaena branches.

$>$ Propose the best-fitted model that could be used to describe knowledge sharing practices among employees.

$>$ Identify which mode of the SECI model is primarily practiced in the Commercial Bank of Ethiopia Hossaena branches.

\section{Methodology of the Study}

The organization selected for this study was the Commercial Bank of Ethiopia. Because CBE has been playing a prominent role in the economic development of the country for 70 years now thus it is the leading bank in Ethiopia, established in 1942. The samples were selected from branch banks of CBE. Purposive sampling method used to select the branches and departments that are conducive for collecting the required data. Considering the branches of the Bank in Hossaena town as one stratum and samples branch of CBE is selected with purposive sampling from the Wolaita District. Data were collected from a randomly selected 85 employees working in thirteen branches found in Hossaena town. This is because the bank operation is highly similar in each branch's even though they are in different districts. The population includes all employees of Commercial Bank Ethiopia in the Hossaena town. The sample individuals selected from the branches were using simple random sampling to give an equal chance of selection to the sample. The research involved in quantitative data analysis techniques. The degree of workers' knowledge sharing practice was examined using the quantitative research method.

\section{Results and Discussions}

The primary purpose of this study was to assess the knowledge sharing practice of employees working in the banking sector. The responses obtained through questionnaires are supplemented with an interview and physical observation. The analysis is done using SPSS version 16.0. Frequency, percentage, means and standard deviation value is used for discussion of the questionnaire collected from commercial bank of Ethiopia Hossaena town branches. Specifically, assessing the existing knowledge sharing practice, identifying the obstacles of knowledge sharing practice, appraising the availability of IT infrastructures and proposing a best-fitted model were issues that this particular study was intended to embark upon.

\subsection{Socio-demographic Characteristics of the Respondents}

To assess the knowledge sharing practice among employees of the Commercial Bank of Ethiopia, the student researcher distributed a total of 100 standard questionnaires and then a total of 85 instruments were returned. Therefore, the response rate was $85 \%$. The data analysis thus continued accordingly. Participants provided basic demographic information regarding their sex, age, educational level, total year of experience, and employment status.

\subsection{Factors Influencing Knowledge Sharing Practice}

As clearly represented in table 1 below, a total of fourteen factors were listed to the respondents to rate the degree of their influence in influencing the availability of knowledge sharing practice. Accordingly, eight of the factors were rated as having a big influence on the practice whereas the remaining six were rated as having a lower degree of influence in influencing the practice of sharing knowledge in the bank. Specifically, 83.6\% of the respondents believed that the existence of rewards and recognition as a major factor in determining the extent of knowledge sharing among employees. A massive amount of respondents, i.e. $77.6 \%$, have also reported that the availability of information technology infrastructure was the promising factor in influencing the culture of knowledge sharing among employees. Besides, $74.1 \%$ of the respondents also agreed that there is Lack of interaction was affecting the degree of knowledge sharing in the organization. Also, $71 \%$ of the respondents agreed that their knowledge-sharing practice was strongly influenced by the lack of formal and informal activities. Formal and informal activities like meetings, training, workshops, orientations, kick-off programs and get-together were, therefore, major factors that hinder workers from sharing their knowledge and experiences. 
The fifth factor deemed to sway the culture of knowledge sharing was organizational culture. A total of $69.4 \%$ of the respondents rated this factor as influential in dwindling knowledge sharing practice. Accordingly, about $68.2 \%$ of the respondents argued that the physical work environment and layout of work offices have been played a great role in restricting the existence of effective knowledge sharing practices. The seventh factor slightly rated from the respondents about $63.5 \%$ of the respondents were in favor of this factor in its influence in declining the knowledge sharing practices of the organization.

Finally, the eighth factor deemed to sway the time of knowledge sharing was a shortage to share knowledge. A total of $57.6 \%$ of the respondents rated this factor as influential in dwindling knowledge sharing practice.

\subsection{Availability of Information Technology Infrastructures}

As far as the presence of IT systems and processes was considered, as shown in Table 2 below, about $81.2 \%$ of the respondents believed that there was the scarcity of IT systems and processes fundamental to cultivate the culture of knowledge sharing among the employees of the organization. About $70.6 \%$ of the respondents were against the presence of user-friendly IT systems in the organizations. About $63.5 \%$, reported the shortage and ill implementation of the internet, e-mail and electronic bulletin boards in the organization which is valuable instruments to share knowledge among each other. Thus, about $77.7 \%$ of the study participants contend that the bank employees are not using then the organization's intranet to share their knowledge. Accordingly, about $74.3 \%$ of the respondents suggest that the portal is not available in the organization for sharing knowledge at a personal level.

Thus, $77.7 \%$ of the questionnaire respondents recognize that the bank has its website for documenting relevant information concerning the program, activity, development, and prospects of the organization. Moreover, $81.2 \%$ of the respondents were against the statement which elucidates whether they store knowledge in the organizations' data base, portal, and intranet. Thus, it seems there are no data base, portal, and intranet for storing personal information in the organization. About $69 \%$ of the respondents reply that they are using manual papers for storing knowledge. Thus, about $66.4 \%$ of the respondents declared that whenever they need information, they have to contact the concerned person face to face than gaining the information they require through IT infrastructures.

\subsection{Knowledge Sharing Models prevailing in CBE}

In this specific study, the SECI (Socialization, Externalization, Combination, and Internalization) model was chosen as a framework because of the aforementioned reasons. Based on this model, an instrument having 11 items was developed to know which model of the SECI model predominantly practiced in the organization. From 11 items the 1-3 for socialization, 4-5 for Externalization, 6-8 for Combination and 9-11 for Internalization. Thus, the result is analyzed descriptively using frequencies and percentages relying on table 3 below.

As clearly depicted items $1-3$ in table 3 , about $68.2 \%$ of the respondents suggest that they are not involving in knowledge management activities; such as in delivering orientations, monitoring and coaching the newly recruited employees of the organization. However, the majority of the respondents, i.e. $52.9 \%$, believed that their staff colleagues are willing to share knowledge with themselves. A 2.64 mean score to this statement also strengthens the assertion that most employees have the willingness to share knowledge among them. Nonetheless, a massive amount of the respondents $(85.9 \%)$ are not sharing information and knowledge valuable to the organization either before or after regular working hours. Socialization is an important aspect of knowledge sharing in organizations. In this mode of knowledge sharing, the tacit knowledge is shared either internally or externally (Glisby and Holden, 2003).

Regarding the practice of the Externalization mode of the SECI model, which implies converting tacit knowledge into explicit one, the researcher attempted to treat the issue by designing two interrelated items $4 \& 5$, as shown in table 3 . Accordingly, about $77.7 \%$ of the respondents believed that they have difficulty raising their ideas during meetings, discussions, training, and workshops organized by the organization. Similarly, a huge amount of the respondents $(90.5 \%)$ witnessed that they are reluctant to share their ideas and knowledge with their colleagues in either communication medias such as through charts, figures, pictures of written form.

According to Nonaka et al. (2000), of the four modes of knowledge conversion, externalization is the key to knowledge creation because it creates new, explicit knowledge from individuals' tacit knowledge. It is believed to be a vital phase for building the culture of knowledge sharing practices in an organization. When tacit knowledge is made explicit, knowledge is crystallized, thus allowing it to be shared by others, and it becomes the basis of new knowledge (Konno et al., 2005).

From table 3 Item $6-8$ about $62.1 \%$ of the respondents report that various documentations of the bank are up to date and timely. $55.2 \%$ of the respondents also believed that new manuals are frequently prepared that are vital to boost up the efficiency of the organization. Similarly, those prepared manuals, brochures, pamphlets and procedures enacted are also distributed to the concerned office or individual quickly. Like the previous one, this idea is also supported by $54.1 \%$ of the respondents. 
The majority of the respondents were against the presence of the internalization phase in the organization. Particularly, $71.7 \%$ of the respondents witnessed that major knowledge gaining circumstances such as training programs, workshops and seminars are not organized for the staff regularly. As a result, the majority of the respondents $(54.6 \%)$ are not fortunate to use the knowledge that could be acquired through these means. The bank is not also facilitating scholarships for those who require escalating their educational level and their knowledge in turn. This contention was supported by about $77.7 \%$ of the respondents.

As seen in the below table 4, the highest score is reported in the combination phase $($ mean $=2.716)$ whereas the lowest score was observed in the externalization phase (1.65). Thinking the 2.50 mean score of scales, only the combination phase is found to be slightly higher than the mean score. The grand mean scores of socialization and internalization were 2.406 and 2.103 respectively. Thus, the result indicated that the bank is dominantly practicing the combination mode of the SECI model. This is to means that the bank is relatively efficient at converting the explicit knowledge of the organization into more systematic sets of explicit knowledge through different means such as books, papers, brochures, pamphlets, etc. On the other hand, externalization was found to be the least practiced phase of the SECI model

\section{CONCLUSION}

The study exposed a difference in knowledge sharing practice among different groups of workers. Concerning the obstacles that play a incapacitating role on employees knowledge sharing practices, lack of rewards and recognition systems, workers' lack of time to share knowledge, employees' low motivation of sharing knowledge, scarcity of IT infrastructures, lack of formal and informal awareness creating activities, lack of interaction among the staff members, physical work environment and office layouts, and interpersonal and communication skills were the major ones. Thus, unless there is an environment of work where these influential factors are eased, the organizations' culture of knowledge sharing could not be improved to the extent it is expected to be. Especially, the organization has to supply itself with the necessary IT infrastructures so that its employees could access it whenever they require sharing knowledge among themselves. The organizations should also look back again and check how knowledge is shared among their employees.

The result of this study shows that the combination is the only mode better implemented in the bank. Even though the implementation of the combination mode of knowledge sharing is appreciated, being reluctant to availing the socialization, internalization and externalization modes has a detrimental effect.

\section{Reference}

Aidemark, J. 2009. "Knowledge management paradoxes", the electronic journal of knowledge management, v7 issue 12009: 1-10.

Glisby, M., Holden, N. 2003."Contextual constraints in knowledge management theory: the cultural embeddedness of Nonaka's knowledge-creating company, Knowledge \& Process Management”, n1 (10): 29-36.

Jakarta, M., and Ratulangi, J. S. 2008. "An introduction to knowledge management: A brief introduction to the basic element of knowledge management for non-practitionersn interesting in understanding the subject". Japan- ASEAN solidarity fund, the ASEAN Foundation, Jakarta, Indonesia.

Mothe, j. D., Gertler. M., Gertler, M., Landry. R., Niosi. J. and Wolfe. D. 2000. "Knowledge management: The new challenge for firms and organization", Innovation system research network (ISRN), n2 (6): 91-100.

Nonaka, I., Toyama, R., and Konno, N. 2000. "SECI, Ba and leadership: a unified model of dynamic knowledge creation", Long Range Planning, n1 (33): 8-17.

Najibullah, A., Darren,G. and Muhammad, K. 2012. "Barriers and enablers of knowledge sharing: a qualitative study of $A B B$, bombardier, ericsson and siemens".

Seyyed, A. A., Daraeia, M. R., and Kalama, R. F. 2012. "Analysis of knowledge sharing in banking industry, Interdisciplinary journal of contemporary research business", n 7(4) http:// www.ijcrb.webs.com.

Yang, T. N. 2011. "Knowledge creation and intellectual capital on securities investment services". African Journal of Business Management, n5 (3), 924-933 
Table 1: Prominent factors affecting knowledge sharing practice in CBE

\begin{tabular}{llllllllllll}
\hline & & \multicolumn{3}{c}{$\begin{array}{l}\text { Strongly } \\
\text { Disagree }\end{array}$} & \multicolumn{3}{c}{ Disagree } & Agree & \multicolumn{3}{c}{$\begin{array}{l}\text { Strongly } \\
\text { Agree }\end{array}$} \\
\hline No & Factor categories & Mean & SD & Freq. & \% & Freq. & $\%$ & Freq. & $\%$ & Freq. & \% \\
$\mathbf{1}$ & Reward and Recognition & 3.16 & .924 & 8 & 9.4 & 6 & 7.1 & 35 & 41.2 & 36 & 42.4 \\
$\mathbf{2}$ & Time & 2.78 & .956 & 7 & 8.2 & 29 & 34.1 & 25 & 29.4 & 24 & 28.2 \\
$\mathbf{3}$ & Lack of Motivation & 2.53 & .781 & 13 & 15.3 & 31 & 36.5 & 34 & 40 & 7 & 8.2 \\
$\mathbf{4}$ & IT Infrastructure & 3.12 & .892 & 5 & 5.9 & 14 & 16.5 & 32 & 37.6 & 34 & 40 \\
$\mathbf{5}$ & Formal/ Informal & 3.00 & .845 & 3 & 3.5 & 21 & 24.7 & 34 & 40 & 27 & 31.6 \\
& Activities & & & & & & & & & & \\
$\mathbf{6}$ & Organizational Culture & 2.87 & .897 & 7 & 8.2 & 19 & 22.4 & 37 & 43.5 & 22 & 25.9 \\
$\mathbf{7}$ & Lack of Interaction & 3.04 & .969 & 8 & 9.4 & 14 & 16.5 & 30 & 35.3 & 33 & 38.8 \\
$\mathbf{8}$ & Absence of Retention & 2.48 & .666 & 4 & 4.7 & 40 & 47.1 & 37 & 43.5 & 4 & 4.7 \\
$\mathbf{9}$ & Physical work & 3.04 & 1.117 & 12 & 14.1 & 15 & 17.6 & 16 & 18.8 & 42 & 49.4 \\
& environment & & & & & & & & & & \\
$\mathbf{1 0}$ & Trust & 2.39 & .846 & 10 & 11.8 & 42 & 49.4 & 23 & 27.1 & 10 & 11.8 \\
$\mathbf{1 1}$ & Fear of misunderstood & 2.58 & .661 & 10 & 11.7 & 35 & 41.2 & 38 & 41.2 & 5 & 5.9 \\
$\mathbf{1 2}$ & Lack of confidence & 2.34 & .780 & 13 & 15.3 & 33 & 38.8 & 36 & 42.4 & 3 & 3.5 \\
$\mathbf{1 3}$ & Selfishness & 2.58 & 1.085 & 20 & 23.5 & 26 & 30.6 & 20 & 23.5 & 19 & 22.4 \\
$\mathbf{1 4}$ & Communication skill & 2.72 & .995 & 13 & 15.3 & 18 & 21.2 & 34 & 40 & 20 & 23.5 \\
\hline
\end{tabular}

Table 2: Availability of Information Technology Infrastructure in CBE

\begin{tabular}{|c|c|c|c|c|c|c|c|c|c|c|c|}
\hline \multirow[b]{2}{*}{ No } & \multirow[b]{2}{*}{ Factor categories } & \multirow[b]{2}{*}{ Mean } & \multirow[b]{2}{*}{ SD } & \multicolumn{2}{|c|}{$\begin{array}{l}\text { Strongly } \\
\text { Disagree }\end{array}$} & \multicolumn{2}{|c|}{ Disagree } & \multicolumn{2}{|c|}{ Agree } & \multicolumn{2}{|c|}{$\begin{array}{l}\text { Strongly } \\
\text { Agree }\end{array}$} \\
\hline & & & & Freq. & $\%$ & Freq. & $\%$ & Freq. & $\%$ & Freq. & $\%$ \\
\hline 1 & IT systems and processes & 1.80 & .910 & 39 & 45.9 & 30 & 35.3 & 10 & 11.8 & 6 & 7.1 \\
\hline 2 & $\begin{array}{l}\text { Employees use internet and e- } \\
\text { mail }\end{array}$ & 2.26 & .990 & 21 & 24.7 & 33 & 38.8 & 19 & 22.4 & 12 & 14.1 \\
\hline 3 & use the organizations intranet & 1.85 & .880 & 36 & 42.4 & 30 & 35.3 & 15 & 17.6 & 4 & 4.7 \\
\hline 4 & Portal is available & 2.08 & .790 & 19 & 22.4 & 44 & 51.8 & 18 & 21.2 & 4 & 4.7 \\
\hline 5 & user friendly IT system & 1.68 & .805 & 42 & 49.4 & 31 & 36.5 & 9 & 10.6 & 3 & 3.5 \\
\hline 6 & $\begin{array}{l}\text { store knowledge in the } \\
\text { organizations' data base, portal } \\
\text { and intranet }\end{array}$ & 1.82 & .819 & 33 & 38.8 & 38 & 44.7 & 10 & 11.8 & 4 & 4.7 \\
\hline 7 & $\begin{array}{l}\text { store knowledge on manual } \\
\text { papers }\end{array}$ & 1.75 & .815 & 39 & 45.9 & 30 & 35.3 & 14 & 16.5 & 2 & 2.4 \\
\hline 8 & $\begin{array}{l}\text { organization has its own } \\
\text { website }\end{array}$ & 1.73 & .836 & 43 & 50.6 & 23 & 27.1 & 18 & 21.2 & 1 & 1.2 \\
\hline 9 & $\begin{array}{l}\text { Employees should contact face } \\
\text { to face to gain information }\end{array}$ & 2.01 & .824 & 25 & 29.4 & 37 & 43.5 & 20 & 23.5 & 3 & 3.5 \\
\hline
\end{tabular}


Table 3: Knowledge sharing SECI mode

\begin{tabular}{|c|c|c|c|c|c|c|c|c|c|c|c|}
\hline \multirow[b]{2}{*}{ No } & \multirow[b]{2}{*}{ Factor categories } & \multirow[b]{2}{*}{ Mean } & \multirow[b]{2}{*}{ SD } & \multicolumn{2}{|c|}{$\begin{array}{l}\text { Strongly } \\
\text { Disagree }\end{array}$} & \multicolumn{2}{|c|}{ Disagree } & \multicolumn{2}{|c|}{ Agree } & \multicolumn{2}{|c|}{$\begin{array}{l}\text { Strongly } \\
\text { Agree }\end{array}$} \\
\hline & & & & Freq. & $\%$ & Freq. & $\%$ & Freq & $\%$ & Freq & $\%$ \\
\hline 1 & $\begin{array}{l}\text { I am involved in knowledge } \\
\text { management activities e.g. in } \\
\text { monitoring and coaching } \\
\text { activities for new entrants }\end{array}$ & 2.8 & .916 & 26 & 30.6 & 32 & 37.6 & 21 & 24.7 & 6 & 7.1 \\
\hline 2 & $\begin{array}{l}\text { Colleagues are willing to share } \\
\text { any knowledge with me }\end{array}$ & 2.64 & .857 & 6 & 7.1 & 34 & 40.0 & 30 & 35.3 & 15 & 17.6 \\
\hline 3 & $\begin{array}{l}\text { Staff members share knowledge } \\
\text { before and after regular } \\
\text { working hours. }\end{array}$ & 1.78 & .807 & 35 & 41.2 & 38 & 44.7 & 8 & 9.4 & 4 & 4.7 \\
\hline 4 & $\begin{array}{l}\text { I raise my ideas on discussions } \\
\text { and workshops }\end{array}$ & 1.96 & .932 & 30 & 35.3 & 36 & 42.4 & 11 & 12.9 & 8 & 9.4 \\
\hline 5 & $\begin{array}{l}\text { I usually share my ideas and } \\
\text { knowledge with } \\
\text { colleagues using charts and } \\
\text { pictures or written form }\end{array}$ & 1.34 & .716 & 66 & 77.6 & 11 & 12.9 & 6 & 7.1 & 2 & 2.4 \\
\hline 6 & $\begin{array}{l}\text { Documentations are up to date } \\
\text { in my bank }\end{array}$ & 2.86 & 1.037 & 10 & 11.8 & 22 & 25.9 & 23 & 27.1 & 30 & 35 \\
\hline 7 & $\begin{array}{l}\text { New manuals are prepared } \\
\text { frequently in my bank. }\end{array}$ & 2.67 & .836 & 5 & 5.9 & 33 & 38.8 & 32 & 37.6 & 15 & 17.6 \\
\hline 8 & $\begin{array}{l}\text { In my banks, new procedures } \\
\text { and manuals distributed } \\
\text { quickly. }\end{array}$ & 2.62 & 1.012 & 13 & 15.3 & 26 & 30.6 & 26 & 30.6 & 20 & 23.5 \\
\hline 9 & $\begin{array}{l}\text { Training programs, workshops } \\
\text { and seminars are frequently } \\
\text { organized for the staff }\end{array}$ & 2.04 & .957 & 29 & 34.1 & 32 & 37.6 & 16 & 18.8 & 8 & 9.4 \\
\hline 10 & $\begin{array}{l}\text { The bank frequently allows for } \\
\text { postgraduate or other } \\
\text { professional training for staff } \\
\text { members }\end{array}$ & 1.81 & .994 & 43 & 50.6 & 23 & 27.1 & 11 & 12.9 & 8 & 9.4 \\
\hline 11 & $\begin{array}{l}\text { I use the knowledge acquired in } \\
\text { training and workshop. }\end{array}$ & 2.46 & .983 & 15 & 17.6 & 31 & 36.5 & 24 & 28.2 & 15 & 17.6 \\
\hline
\end{tabular}

Table 4: Grand mean scores of the SECI model phases

\begin{tabular}{lllll}
\hline & \multicolumn{4}{l}{ Modes of the SECI Model } \\
\cline { 2 - 5 } Grand mean score & Socialization & Externalization & Combination & Internalization \\
\hline
\end{tabular}

